\title{
Atlantis
}

Critical Studies in Gender, Culture \& Social Justice

Études critiques sur le genre, la culture, et la justice

\section{Snapping: Feminist Pedagogy and Navigating the "New" Right}

\section{Heather Latimer}

Volume 41, Number 1, 2020

URI: https://id.erudit.org/iderudit/1074017ar

DOI: https://doi.org/10.7202/1074017ar

See table of contents

Publisher(s)

Mount Saint Vincent University

ISSN

1715-0698 (digital)

Explore this journal

Cite this article

Latimer, H. (2020). Snapping: Feminist Pedagogy and Navigating the "New" Right. Atlantis, 41(1), 72-81. https://doi.org/10.7202/1074017ar

\section{Article abstract}

This paper uses anecdotal and affect theory to think through the repercussions of feminist pedagogy while navigating the "new" right. It extends Sara Ahmed's metaphors of the feminist snap and the feminist ear as pedagogical and epistemological tactics.
All Rights Reserved @ Heather Latimer, 2020

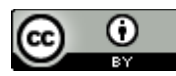

This document is protected by copyright law. Use of the services of Érudit (including reproduction) is subject to its terms and conditions, which can be viewed online.

https://apropos.erudit.org/en/users/policy-on-use/ 


\section{Snapping: Feminist Pedagogy and Navigating the "New" Right}

Heather Latimer is Assistant Professor of Gender and Women's Studies at the University of British Columbia, where she teaches courses on reproductive politics, feminist epistemologies, and critical sexuality studies. In general, her research aims to understand and explain the history of reproductive politics by studying representations of reproduction, specifically in science fiction and film.

Abstract: This paper uses anecdotal and affect theory to think through the repercussions of feminist pedagogy while navigating the "new" right. It extends Sara Ahmed's metaphors of the feminist snap and the feminist ear as pedagogical and epistemological tactics.

Keywords: affect theory, anecdotal theory, feminist pedagogy, Sara Ahmed, the "new" right
T teach four classes at the University of British 1 Columba (UBC) the day after the 2016 United States (US) election of Donald Trump. Students openly weep in all of them. Some students are inconsolable and one has a panic attack. The despair is palpable. For some students this continues for weeks, and one student, a young, queer American, stops coming to class. She eventually drops out. When I give firstyear students time to journal anonymously about the election and ask them to hand in anything they want or need me to see, I am shocked and dismayed when two students hand in entries in support of Trump. These two students tell me they are hesitant to share their feelings in class, which are that Trump is a muchneeded corrective to "reverse sexism," that they believe "political correctness" is out of control, and that they are worried they will be punished for standing up for their values in class.

In an upper-level class an Indigenous student becomes increasingly upset at the emotional reactions other students are having to the Trump administration. She rolls her eyes and crosses her arms as other students cry when talking about their fears for the future. I invite the student to speak. Somewhat reluctantly, she tells the class that her exasperation comes from the all the "white tears." She says, "I'm sorry you don't feel safe right now, I'm sorry this is hard for you. But we've always known we weren't safe." She invites students to a protest for Standing Rock. There is little uptake. It is almost as if the student had not spoken. Suddenly she shouts: "We don't need your tears. We need your bodies."

In a course focused on intersectional approaches to health disparities, the class strategizes about what we can do to feel more engaged in our communities. We 
make a list on the board. I talk about supporting local reproductive justice groups and movements. Unbeknownst to me, a student is recording me. Later, she will tell other students that I acted unprofessionally. She will also write this in her student evaluations. I will only find out she was recording me after she and another student get into a physical altercation at an anti-abortion demonstration. I am told the recorder has been collecting evidence against me. In my course evaluations she will write that I "coerced" students into donating to political organizations of my choice, and that I made the classroom an "unsafe space" for white, conservative, pro-life Christians.

A first-year student hands in his final paper proposal. He wants to write about Jordan Peterson, Bill C-16, and "compelled speech." $\mathrm{He}$ is interested in UBC's Free Speech Club, which, in the club's own words, "seek[s] to promote an open debate stage, where political correctness no longer holds sway" (UBC Free Speech Club 2020). The club is part of a larger trend across campuses in North America to embrace the Chicago Principles, a set of guidelines for universities regarding "free speech," which claims "it is not the proper role of the University to attempt to shield individuals from ideas and opinions they find unwelcome, disagreeable, or even deeply offensive" (Stone et al. 2014). As part of this mandate, UBC's Free Speech Club has gone out of its way to invite controversial, conservative speakers to campus, such as Ben Shapiro, Andy Ngo, and Jordan Peterson, some of whom are seen as heroes by the alt-right. ${ }^{1} \mathrm{I}$ remind my student that he needs at least five peer-reviewed articles or book chapters for his research paper. I also request he read the Canadian Charter, Bill C-16, and the corresponding sections of the criminal code that it amends, if he wants to take up this topic. We meet several times, I review and reject two paper proposals, we share countless emails, and I help him access and evaluate scholarly sources. Eventually, he hands in a paper that is exceptional, not because of its content but because of its tone, which is defeated and frustrated. He was unable to find evidence to support his position that using someone's preferred pronouns is a form of compelled speech. He concludes that Bill C-16 is not the threat to freedom of speech that he thought it was and is instead, in his own words, "appropriate." I feel a mixture of relief and pride in how I handled this situation until I realize that I have spent as much time mentoring this single student as sixty-five other firstyear students, combined.

I share these anecdotes as a way to provide a sense of the scenarios that spurred my thinking in relationship to this special issue, and to provide context and structure to the comments I want to make. In doing so I engage in what Jane Gallop calls "anecdotal theory," as a way to privilege my students' and my own experiences as the foundations of my knowledge. As Gallop explains, anecdotal theory involves recounting an incident and then attempting to read that account for the theoretical insights it affords in the present (2002, 2). While some might think the terms "anecdote" and "theory" may have opposing purposes or connotations, Gallop suggests it is precisely anecdotes' "ability to intervene in contemporary theoretical debates" that makes them interesting, because they honour "the uncanny detail of lived experience" (ibid.). They therefore contribute to the "project of making knowledge that better opens to the real" (ibid., 9). The anecdotes I share, then, are "meant neither as confessions nor simply as the representation of experience," but are a way to bring these events into new light through writing and reflecting on them (Feigenbaum 2007, 340). While I am hoping that some of the scenarios might resonate with readers, and provide an entry point for shared thinking about pedagogical strategies for teaching social justice at the present moment, I realize that anecdotes are encounters in and of themselves, telling stories of partial perspective, while hopefully opening up lines of thought (ibid., 346). This is why Gallop describes anecdotal theory as situated, or as "theory in the flesh of practice" (Miller qtd in Gallop 2002, 158). It requires an embedded and responsive movement between the seemingly particular (the experience) and the generalizable (theory) (Loveless 2011, 27). Anecdotal theory requires looking at a series of events with a reflexive engagement not only with the incident itself, but with the occasion for theorizing. 
These shared memories are moments of pedagogical crisis, but they are different kinds of crisis happening with different kinds of students. At first, I struggle to find a common thread. I know the first scenario is the one that fits best into the dominant discourse on teaching right now, in what is being described as the post-truth era: students and faculty expressing shock and horror about the election of Donald Trump, and about government platforms and policies that so blatantly support white supremacy, misogyny, and xenophobia; a feeling that the ground has shifted beneath us in ways for which we were unprepared; and a simultaneous realization that this shift has begun to have everyday consequences in our classrooms. Students, for instance, suggesting that a professor is biased because they teach about structural oppression in a class focused on social justice. The fourth scenario, the first-year student who has been swept up in the altright rallying cry to protect free speech, also fits into this reading, as does my investment in them, and my hope and desire that they will overcome their biases and assumptions through scholarly reading and writing.

There is much evidence to support reading all of these scenarios as directly informed by our current political moment. From the vicious harassment and attacks directed at UBC's Mary Bryson after their debate with Jordan Peterson, to the rise of so-called free speech clubs and white student unions at Canadian universities, to the creation of the "Professor Watch List" in the US, to the United Conservative Party's recent announcement that they will soon require post-secondary institutions in Alberta to adopt the Chicago Principles - it is clear that the atmosphere on our campuses has shifted. Even further, the alt-right is a real presence in our classrooms, recruiting by following Richard Spencer's strategy to "get them while they are young" because "people in college are at this point in their lives where they are actually open to alternative perspectives" (qtd. in Harkinson 2016). And, this rise in white nationalist, xenophobic, and sexist thinking has serious risks and consequences for those of us engaged in social justice pedagogy. Yes, it is possible that a student may have recorded me and complained about me a decade ago, but I don't think I am alone in seeing that kind of behavior as part of a larger trend to monitor the conduct of Women's and Gender Studies faculty members. Nor do I think I am alone in seeing this kind of behavior as also increasingly being understood as what one should or might learn to expect when teaching social justice. We need only think about the situation with Lindsay Shepherd and Dr. Nathan Rambukkana at Wilfrid Laurier University, in which Dr. Rambukkana was recorded without his knowledge, to see this new normal at work; networks exist to circulate recordings of professors in order to harass them or attempt to get them fired. Indeed, as Shama Rangwala has recently argued, the "free speech issue" on our campuses is really a smoke screen for a larger trend. It is part of "a global mobilization of institutions for the right," which use the free speech issue to provide "rhetorical cover" to actually suppress critiques of power (2019). This also explains why the alt-right is so focused on being given a platform at universities, as such a platform simultaneously "provides legitimation of their ideas and delegitimization of the academy" (ibid.). As bell hooks wrote more than thirty years ago, if the work of our discipline is to question "the ideological structures of the prevailing white-supremacist, patriarchal hegemony," it is "fitting that the university be identified as a useful site for radical political work," and we must therefore assume "our work can be and is undermined" by those with an interest in maintaining hegemonic structures $(1989,36)$. In other words, if the university's purpose, in its own words, is to pursue "excellence in research, learning, and engagement to foster global citizenship and advance a sustainable and just society" ("UBC's Vision, Purpose and Values" 2020), then no wonder it is a target.

Several cultural critics would likely support an analysis that these anecdotes are reflective of the times. For instance, Henry Giroux, perhaps one of the best-known international scholars of critical pedagogy, claims that we have now entered an "emerging political-social formation in which fake news becomes the accepted mode of shaping public discourse, inexperience and incompetence become revered criteria for holding public office, and social responsibility is removed from any 
vestige of politics" (2016). As neoliberal regimes wage "a major assault on critical education and the public spheres in which they take place," he further claims that "thinking has become dangerous" (ibid). Other educators agree with Giroux, pointing out that the educational implications of radical right discourse for the broader public is that the alt-right is shaping how people think and act inside and outside of the classroom (Miller-Idriss \& Pilkington 2018). These critics claim that in the face of white supremacy and a rise in populism, we must develop and reclaim a radical pedagogy, "as a form of educated and militant hope," beginning, as Giroux suggests, with recognizing that education is about "the capacity for liberatory change," and is "a cultural, political, and moral force" (2016).

However, as the student in my second anecdote, the one who became fed up with their classmates' tears, importantly demonstrates, not everyone is shocked by the "sudden" onslaught and resurgence of sexism, racism, xenophobia, homophobia, and transphobia we are witnessing. For instance, the long, thorough, and structural inhospitability of colleges and universities to racialized, Indigenous, queer, and gender non-conforming people is not new (Kuokkanen 2007). Nor is having racialized faculty members unequally share the affective risks in the course of critical reflection, when "discovering" or "debating" structural inequalities in our classrooms (Razack 1998, 50). Thinking has always been dangerous. Some people have always been vulnerable. And, despite what Giroux claims, we already know that education is "a cultural, political, and moral force," and one that is not always used for liberatory purposes. Returning to bell hooks, for example, she has repeatedly demonstrated that systems of domination, always at work in the academy and in the classroom, silence marginalized voices: "Racism, sexism, and class elitism shape the structure of classrooms, creating a lived reality of insider/outsider that is predetermined, often in place before any class discussion begins" (hooks 1991, 176).

To acknowledge this isn't to claim that everything is the same as it was thirty years ago, nor is it to downplay what is currently happening. It isn't to ignore the horrific, vicious harassment of those targeted by alt- right trolls. It isn't even to say that thinking isn't more dangerous right now, nor is it to cynically claim that this is just the way things are. Rather, it is to say, much like my student attempted, that we need to historicize this specific political moment as part of the ongoing project of settler colonialism, as shaped by the failings of neoliberal globalization, as connected to a racial ontology that is deeply rooted in modernity, and as related to what Harsha Walia has termed "border imperialism," or the contemporary practices of empire (2014). And, that we therefore need to reframe our affective response of "shock," accordingly. As Aimee Rowe and Eve Tuck argue, we need to turn to "where we already were" in order to analyze this moment $(2017,6)$. What they mean is that as we examine the "new" ways gendered and racialized systems of power are taking shape inside and outside our classrooms, for example, we need to attend to how those systems of power came into being, and continue to operate at a foundational level through the logics of the past; for instance through the racialized system of settler colonialism, or through a long history of anti-Black racism, or through contemporary practices of imperialism, as mentioned above.

Indeed, as Rowe and Tuck suggest, the past not only shapes our everyday practices and politics, but also haunts "our intellectual projects" in a manner they describe, following M. Jacqui Alexander, as "a ghostly shape" that "must be interrogated to show its form" (ibid., 6). We can see this ghostly shape in the "social, material, and rhetorical practices" of universality, which construct the universal subject (read: white) "as a settler subject" (ibid., 9). We can also see this ghostly shape in the "unwitting reproduction of settler logics," which Rowe and Tuck describe as so foundational to knowledge production that we can't even imagine the "sovereign subject" - the human being who can understand themselves as a self, the very subject we imagine we are teaching-without these logics (ibid., 7; 9). We can also see it in how we determine who is conceptualized as fully human (affecting, selfdetermined, legitimate) inside our classrooms, a determination that is based on a process of racialization, whereby being seen as the sovereign subject is contingent on the "the capacity to 'affect' and not be affected by others," a capacity that is often difficult for racial- 
ized peoples because of the ways that sovereignty is organized and experienced (ibid., 9). Paying attention to how this ghostly shape continues to haunt our classrooms, therefore, requires "attention to the uneven distribution of affects and affective processes - the very constitution of some subjects as always-already affecting, while 'others' are slotted as 'affectable'" (ibid.). It requires acknowledging that we operate on an uneven playing field in our classrooms, historically, materially, and affectively, and that what might seem newly ghoulish about the present moment to some is a reanimation of the past for others. However, this difference is hard to grasp when you have been slotted as affecting, as in control, as sovereign rather than as affectable. This is why it really should not come as a surprise that my student was not shocked by Trump's election, nor that her lack of shock was not acknowledged by the other students. It is often hard to hear someone who challenges the unwitting logic of sovereignty that Rowe and Tuck outline. It is hard to hear someone who insists that what feels new is actually old again.

My student's refusal to allow shock to be the communal response to Trump's election was ignored. She was not heard. Instead, she hit what Sara Ahmed describes, in Living a Feminist Life, as an institutional "brick wall" (2017a, 136). As Ahmed outlines, such a wall "is not real in the sense of a tangible thing, what is perceptible through touch," but the metaphor of the wall conveys the experience of attempting to challenge or change norms: "a wall is what you come up against. It is a physical contact; a visceral encounter" (ibid.). Being unheard is like hitting a brick wall. "When you bring up walls, some people just blink" (2017a, 147). She further elaborates:

Making feminist points, antiracist points, sore points, is about pointing out structures that many are invested in not recognizing. That is what an institutional brick wall is: a structure that many are invested in not recognizing. It is not simply that many are not bruised by this structure. It is also that they are progressing through the reproduction of what is not made tangible. When we are talking of sexism as well as racism, we are talking about systems that sup- port and ease the progression of some bodies. (ibid., 158)

My student did not progress. The non-response of the white-majority students in the rest of the class acted as a brick wall. In fact, even as a teacher with years of experience listening to students, it was only later that I was able to sense the materiality of that wall: "materiality: if we are hit by something, we become conscious of something" (ibid.,138). And becoming aware was not due to my effort, but hers. As Ahmed argues, when we finally notice a brick wall that was previously invisible to us, "it is the effort of a diversity worker; of her blood, sweat, and tears" (ibid.,139).

I wonder how many times my student hit that wall before I noticed. I wonder how many other walls I don't notice today. I wonder how many times I have capitulated to what Stefano Harney and Fred Moten describe in The Undercommons as the university's "desperate business" of upholding the sovereign subject that Rowe and Tuck criticize $(2013,37)$.

Another thought: I assume if you are reading this that you are likely committed to some form critical pedagogy, whether you engage in pedagogies of discomfort (Henry 1994), oppositional pedagogies (Mohanty 2003), or post-oppositional pedagogies (Keating 2016), all of which rely on allowing teachers and students to experience discomfort, and on questioning students' political beliefs, as well as dominant institutional and social structures. Perhaps you already see the classroom as a potential space of intellectual and political struggle, and expect moments of crisis. As worldviews and ideological groundings are destabilized and rebuilt, students can become frustrated, defensive, angry, and anxious. Maybe you understand yourself as a learner and not just a teacher, take a student-centered approach, or try to move beyond "either/or" thinking.

Are the above anecdotes really an indication of just how much the ground has shifted, then? Or, has the shifting ground simply uncovered or exposed cracks that were already there, revealing the limitations present in the kind of pedagogy we are able to enact in 
any university, as Rowe and Tuck suggest. In other words, perhaps these moments are a reminder of what Robyn Wiegman has pointed out about the investments in our own discipline, and its reliance on progress narratives. As Wiegman outlines, in our desire for the field of Gender and Women's Studies to be understood and seen as inclusive and progressive, as knowable and representative, we are driven to find and to locate the "right" object of study, in the hopes that our analyses will be "adequate to the political commitments that inspire" them $(2012,3)$. We are desperate "for feminism to offer us the means to manage the incommensurable and the inexplicable, to overturn pain and indifference, to move us beyond the agony of our own unknowing, and thereby to provide us with some words that we can learn once and securely for all” (Wiegman 2004, 164). The cruelty of this investment, however, as Lauren Berlant has shown us, is that we are bound to be disappointed by our optimism. As Berlant states, "deep in the ambitions and socialization of the feminist teacher" is the promise "to make learning personal, socially transformative, and generationally supportive" (1997, 153), something that "motivates taking on all kinds of therapeutic and mentoring functions that are way beyond our expertise" (ibid., 154). Even further, implicitly promising the defeat of racism, xenophobia, misogyny, and homophobia, goals which are impossible to attain in the space of one semester together, often leads to "puzzlement, exhaustion, and feelings of domination, isolation, and abandonment for students and teachers both (ibid., 153).

Yes.

Yes.

I want students to feel, to act, to transform. This is the critical pedagogy I want to practice. I want to enact what bells hooks describes as "the feminist classroom," a place where there is a sense of struggle, yes, but also "a visible acknowledgement of the union of theory and practice, where we work together as teachers and students to overcome the estrangement and alienation that have become so much the norm in the contemporary university" $(1989,51)$. This is a place that hooks describes as relying on conversation, on sharing information, and on exchanging ideas $(2013$, 44). But, following Wiegman and Berlant, I realize that there are aspects of the feminist classroom that I cannot manage, that I don't have the institutional support to enact, that involve taking on therapeutic and mentoring functions beyond my expertise, and that lead to those feelings of exhaustion that Berlant describes, for me and my students both. And, to this I want to add that while I am attached to a pedagogy in the manner hooks outlines, there are also some conversations I don't want in my classrooms. And, I'm not sure I should want them, such as when a student is racist, or transphobic in the name of "free speech," or because they like to "play the devil's advocate," or when the feelings, words, or actions of one come at the expense of sixty-five others - even if there is the promise of a transformation, such as I recounted in my fourth anecdote.

*

These are serious questions: Should I care if my classroom is an unsafe space for anti-abortionists? Is it okay if I create an environment where students are fearful of sharing transphobic, racist, and sexist thoughts and opinions? Does the present political moment require that I let go of the fantasy of a liberatory pedagogy? How do I remove brick walls for some students while setting up boundaries for others?

In a chapter titled "Pedagogy," from Rethinking Women's and Gender Studies, Susanne Luhmann grapples with similar questions. She asks:

What if the classroom does not feel liberatory to the teacher and/or to the students? Indeed, what do we make of students who complain of the "oppressiveness" of WGS [Women's and Gender Studies]? How do we make sense of students who refuse the emancipation WGS teaching proffers? Is this the sign of the failure of the teacher, the curriculum, the students, the institution, or of all of us? $(2012 ; 67)$

Luhmann claims that students' refusal to identify with a feminist curriculum "can tell us something about the complex process that is learning (that is, if we understand learning as exceeding the realms of both the soci- 
ological and of consciousness)" (ibid., 76). Following this, she suggests that obstacles to learning in the feminist classroom can be "of a social nature: a repressive institution, insufficient curricular representations, a patriarchal knowledge culture that silences women's voices, experiences, feminist critiques, and so on," but they can also be internal in that "the inner psyche -affects such as love and hate-and their histories, also affect how students attach to knowledge" (ibid., 78).

I like this idea-that obstacles to learning are internal as well as external. It's an idea that helps explain the defeated, frustrated tone of the student who wanted so badly to find scholarly research that supports Jordan Peterson. It also helps explain the fury of the student who recorded me, as well as my own astonishment when I realized I had Trump supporters in my class. It even helps explain why the student who recorded me called me "unprofessional": as Harney and Moten assert, we are unable to enact a radical pedagogy in the corporate university without being seen this way (2013, 68). Finally, Luhmann's idea helps me see that what we often label as "feelings" in the classroom are not just emotions, but thoughts, experiences, and phenomena, and external as well as internal frameworks. As Sarah Chinn explains, "emotion is not just evanescent or situational, but part of larger experiential frames through which we understand the world in which we live. These frames shape and are shaped by not just material conditions; they are also the building blocks of 'affective elements of consciousness and relationships: not feeling against thought, but thought as felt and feeling as thought" $(2012,16)$. For instance, unlike discussing "social and political structures that, once recognized, can be analyzed and anatomized" feelings "both explain those structures and can obscure them" (ibid.). This is perhaps why all of us, not just students, have trouble separating our emotions from the politicized thinking and writing that informs much of our discipline, and much of our course content; they are deeply intertwined. But maybe this also means that we can evaluate our feelings like we do our thinking, and make judgements about which ones need revision, development, or further reflection, about which ones are the external and internal obstacles to learning that Luhmann describes.
Speaking of feelings, it is the student in scenario two that I think about most often, the one who took on the role of what Sara Ahmed describes as the feminist killjoy: the person who points out structural inequalities at an inconvenient time and is often punished. In this case, we can call my student a killjoy because she stopped her classmates from enjoying a good cry. She tried pushing back against their feelings.

Ahmed describes the consequences of being the killjoy - how the resistance to the killjoy's presence presses against the body like a physical force, how it feels like coming "up against something that does not move, something solid and tangible" $(2012,26)$. As I described above, it is like hitting a brick wall. It reminds me of Ahmed's line that "if you have to shout to be heard you are heard as shouting. If you have to shout to be heard you are not heard" (2017b). Ahmed describes moments like these as a snap-like the harsh snap of a twig, or the sound of breaking: "Sharp, brittle, loud" (2017a, 189). For her, the sharpness matters, as well as the temporality. The snap must be "a sudden quick movement. The speed of snapping might be how a snap comes to be apprehended as a movement at all" (ibid., 188). What she suggests is that in this movement-quick, loud, harsh-the killjoy registers the loss of what others wish to retain. Similarly, Erin Wunker describes the killjoy as someone who will not be contained or coerced into "the social narratives that are prescribed for her" $(2016,46)$. The response to the killjoy's refusal to play along, however, is that she is seen as snapping, as out of control, as the problem.

But, it can also be that the killjoy creates a break, a snap with what was there before, by opening up opportunities for others to snap: "by snapping we become feminist ears; we become willing to receive" (Ahmed 2017b). That is, by snapping we allow others to snap too, because "a snap sounds like the start of something, a transformation of something" (Ahmed 2017a; 188). It is a "feminist communication system" (ibid., 211). Snapping is not just an individual action, therefore, although it often starts with an individual, but is what happens when an "irritation" comes to the social surface, "as some tan- 
gible thing, as a situation that should not be patiently endured, as a situation that demands our collective impatience" (ibid., 211). Like my killjoy student's outburst, then, snapping happens because of a sudden feeling of "too much." It is "about the intensity of a situation: when you are asked to do something and you experience that request as too much, this time, even if you have done it before" (ibid., 200). In this case, maybe watching the majority-white students cry in shock and dismay at Trump's election was too much, even if she had been able to watch such behavior before in similar circumstances.

Ahmed suggests that in his moment of "too much" we can be reoriented towards what she describes as new kind of optimism, different than the Berlant's cruel one, in that it is "an optimism without a future, an optimism that makes a break of something the start of something without knowing what this something is" (ibid., 200). This is an optimism that does not hang its hope on what comes next, but on recognizing that the present situation is impossible to sustain. This is an optimism that relies on us realizing we are sometimes part of institutions that make others snap. In a similar vein, in the introduction to The Undercommons Jack Halberstam asks: "If we do not seek to fix what has been broken, then what? How do we resolve to live with brokenness, with being broke...?" (2013, 5). While Halberstam is questioning the university as an institution, wondering what is salvageable, if anything, I think these questions are applicable to Ahmed's idea of snapping, as well as to my observations here. How do we resolve to live with brokenness?

Well, Ahmed suggests that "to be complicit should not become its own reproductive logic: that all we can do is to reproduce the logics of the institutions that employ us. In fact, those who benefit from an unjust system need to work even harder to expose that injustice" (Ahmed 2017a., 263). What I think she means is that those of us who are in regular employment in the university system must learn to kill joy, even some of our students' joy. Otherwise, we risk losing the potential for hearing and being part of a collective snap, and risk losing the potential for being open to this optimism that is not about the future, but about making a break with the present. I think she is saying that we should start from this position and enact solidarity with the students who are snapping. We should cultivate a feminist ear.

Perhaps, then, the metaphor of the feminist ear is one we might find useful right now. Maybe cultivating a feminist ear could allow us to break down, kill, or at least examine some of the very things we assume we should retain in our pedagogy, in order think about strategies for teaching in the face of the "new" right. As my anecdotes demonstrate- and this special issue indicates - many students are making noise. But not all of them are snapping. The difference is that snapping has the potential to give us "the energy to rebel" (Ahmed 2017a, 255). The difference is that snapping is an invitation to snap. In order to hear the difference between a noise and a snap, however, "one must slow down" and "bring to the surface what is around the story" (ibid., 200; 209). One must attend to those external and internal barriers to learning and how they are intertwined in feeling. And, one must attend to who is slotted as affectable and who is slotted as affecting in our classrooms. This has been my intention with this essay: to wade through the noise of the current moment and tune my ear to those whose snapping can reorient me. If, as Gallop suggests, an anecdote is a reorganization of time that allows for the creation of a new perspective, it is also my hope that by sharing these anecdotes I am enacting one strategy for learning to hear differently. 


\section{References}

Ahmed, Sara. 2017a. Living a Feminist Life. Durham: Duke University Press.

2012. On Being Included: Racism and Diversity in Institutional Life. Durham: Duke University Press.

. 2017b. "Snap!" Blog, May 21, 2017. Feminist Killjoys. https://feministkilljoys.com/2017/05/21/ snap/.

Berlant, Lauren. 1997. "Feminism and the Institutions of Intimacy." In The Politics of Research, edited by Ann E. Kaplan and George Levine, 143-161. New Brunswick: Rutgers University Press.

Chinn, Sarah. 2012. "Once More with Feeling: Pedagogy, Affect, Transformation." Transformations: The Journal of Inclusive Scholarship and Pedagogy 22, no. 2: 15-20.

Feigenbaum, Anna. 2007. "The Teachable Moment: Feminist Pedagogy and the Neoliberal Classroom." Review of Education, Pedagogy, and Cultural Studies 29, no. 4: 337-349.

Gallop, Jane. 2002. Anecdotal Theory. Durham: Duke University Press.

Giroux, Henry. 2016. "Trump's Second Gilded Age: Overcoming the Rule of Billionaires and Militarists." Counterpunch. https://www.counterpunch.org/ 2016/12/09/trumps-second-gilded-age-overcomingthe-rule-of-billionaires-and-militarists/.

Halberstam, Jack. 2013. "The Wild Beyond: With and For the Undercommons." In The Undercommons: Fugitive Planning and Black Study, by Harney, Stefano, and Fred Moten, 2-13. New York: Minor Compositions.

Harkinson, Josh. 2016. "The Push to Enlist 'Alt-Right' Recruits on College Campuses." Mother Jones. https:// www.motherjones.com/politics/2016/12/richardspencer-alt-right-college-activism/.
Harney, Stefano and Fred Moten. 2013. The Undercommons: Fugitive Planning and Black Study. New Yok: Minor Compositions.

Henry, Annette. 1994. "There are No Safe Places: Pedagogy as Powerful and Dangerous Terrain." Action in Teacher Education 15, no. 4: 1-4.

hooks, bell. 2013. Teaching Community: A Pedagogy of Hope. New York: Routledge.

. 1991. "Essentialism and Experience." American

Literary History 3, no. 1: 172-183.

. 1989. Talking Back: Thinking Feminist,

Thinking Black. Boston: South End Press.

Keating, Analouise. 2016. "Post-Oppositional Pedagogies." Transformations: The Journal of Inclusive Scholarship and Pedagogy 26, no. 1:24-26.

Kuokkanen, Rauna. 2007. Reshaping the University: Responsibility, Indigenous Epistemes, and the Logic of the Gift. Vancouver: UBC Press.

Loveless, Natalie. 2011. "Reading with Knots: On Jane Gallop's Anecdotal Theory." S: Journal of the Jan van Eyck Circle for Lacanian Ideology Critique 4: 24-36.

Luhmann, Susanne. 2012. "Pedagogy." In Rethinking Women's and Gender Studies, edited by Catherine Orr, Ann Braithwaite, and Diane Lichtenstein, 65-81. New York: Routledge.

Miller-Idriss, Cynthia and Hilary Pilkington. 2018. Gender and the Radical and Extreme Right: Mechanisms of Transmission and the Role of Educational Interventions. New York: Routledge.

Mohanty, Chandra Talpade. 2003. "'Under Western Eyes' Revisited: Feminist Solidarity through Anticapitalist Struggles." Signs 28, no. 2: 499-535.

Rangwala, Shama. 2019. "Free Speech and the University: A Closer Look at the Chicago Principles." Pyriscence, May 30, 2019. https://www.pyriscence.ca/ home/2019/5/30/chicagoprinciples. 
Razack, Sherene. 1998. Looking White People in the Eye: Gender, Race, and Culture in Courtrooms and Classrooms. Toronto: University of Toronto Press.

Rowe, Aimee Carrillo and Eve Tuck. 2017. "Settler Colonialism and Cultural Studies: Ongoing Settlement, Cultural Production, and Resistance." Cultural Studies <-> Critical Methodologies 17, no. 1: 3-13.

Stone et al. 2014. "Report of the Committee on Freedom of Expression.” https://provost.uchicago.edu/ sites/default/files/documents/reports/

FOECommitteeReport.pdf.

UBC Free Speech Club. 2020. Facebook homepage. Accessed May 23, 2020. https://www.facebook.com/ pg/TheFreeSpeechClub/about/?ref=page_internal.

University of British Columbia. 2020. “UBC’s Vision, Purpose and Values.” Accessed May 23, 2020. https:// www.ubc.ca/about/vision-values.html.

Walia, Harsha. 2014. Undoing Border Imperialism. Oakland: AK Press.

Wiegman, Robyn. 2012. Object Lessons. Durham: Duke University Press. . 2004. "On Being in Time with Feminism."

MLQ: Modern Language Quarterly 65, no. 1: 161-176.

Wunker, Erin. 2016. Notes From a Feminist Killjoy:

Essays on Everyday Life. Toronto: BookThug 